\title{
MOTIVATION THEORIES FOR PREPARING POPULATION TO CRISIS SITUATIONS
}

\author{
Luboš Mahdoň, PhD \\ Faculty of Security Engineering University of Žilina, Slovakia, \\ E-mail: mahdon@zilinskyadvokat.sk
}

\begin{abstract}
Crisis situation, as indeed is clear from the very concept of a "crisis" mostly very hard predictable phenomenon, something unusual, differing from the events regularly and predictably repeating and if there is, will threaten a large number of people, property and the environment. Motivation theory to prepare population to crisis situations are extensive and this issue is addressed by several experts as well as laymen. The actual motivation is divided into two groups, both psychological and sociological scientific discipline. Motivation of population is a very complex process, as there are activated internal assumptions guiding the action of a person to fulfill a certain goal, or of trying to meet certain targets. The motivation of citizens and their approach to crisis phenomena is possible to use several theories and methods to increase interest population preparedness in case of crisis. It is important that the society was motivated by the fact that individuals respond properly and deal with the consequences of crisis events. People are aware of the risks to their life, health or property only when participating directly in accidents or natural disasters. Although individuals can not reverse the course of events of crisis phenomena, can conduct an appropriate choice to significantly reduce its effects in your area by using the theories that are useful for practice.
\end{abstract}

Keywords: motivation, theory, method, crisis situation, analysis. 


\section{Introduction}

There are several theories seeking principles, patterns, methods and tools on how to effectively motivate people and how to direct itself to prepare for crisis situations. The basic principle is an explanation of motivational theories, their analysis and subsequent application to practice. Consequently, if this necessary to look back into history, what was the motivating people a good starting point and vice versa, which is to motivate misleading, almost unusable in the future. Generally it is possible to understand the readiness of the population to the crisis situation in three areas such as education, prevention and motivation in theoretical or practical level, important for theoretical reflection area, from which it leads to the practice.

\section{Analysis of the present practical solutions and motivation citizens on crisis preparedness}

Preparedness in case of emergency and crisis phenomena is the responsibility which must involve State or public authorities, other legal entities and individual citizens. Preparedness in case of danger can best be achieved if the targets are well known teaching people the contents of education, forms, methods and means of education, motivational techniques and instruments and the expected results of the action plan for crisis events. Following consultations with expert's civil protection education and training of experts and citizens on crisis phenomena carried out today under three basic premises:

What is important to learn?

Everyone should think about the dangers and risks to the public. It should have an overview of the protection plans that have been developed for the purpose of prevention and management of crisis events, and mitigate their impact on human lives and material values

Who should learn it?

Elected officials - in order to obtain their support for the plan of protection in the event of crisis phenomena 
The rescue organizations - to emphasize collaborative search and rescue operations.

Ordinary citizens - to know what to do and how to behave in the event of a crisis phenomenon.

How to learn it?

The method of education of residents in emergency preparedness, i.e. in the field of civil protection should be carried out mainly in three forms, education, training and exercises.

Education:

To tackle the issue of readiness of the population to crisis phenomena is essential to continuing education. This can be ensured through different courses, lectures and seminars. Finally, we also cannot forget the power of the media and also the internet.

Training:

As far as the application of theoretical knowledge into practical design, thus training it can be concluded that this constitutes a significant part of future success. It is therefore in the first place in terms of emergency situations and without this element is almost impossible these situations satisfactorily.

\section{Exercises:}

The exercises are a necessary step in the preparation for crisis phenomenon. The aim of the exercises to cope with the crisis phenomenon is improving preparedness in the event of a crisis phenomenon, increase operational readiness and ability to respond. Exercise consists of the performance of duties, tasks or operations manner very similar to those that could be implemented in case of a real crisis phenomenon.

Public exercises:

Exercises to the public to attract and keep the interest of people to participate actively to avert the consequences of crisis events or crisis situations that stimulate the enthusiasm and practical knowledge and skills practice, reviewed, evaluation and improvement plans and operational capabilities by revealing weaknesses in the planning and resources and test equipment and operating instructions. Appropriate means of education in the context of preparedness for crisis events are the mass media such as print, radio, television, internet and cinema advertising - billboards.

The main forms of preparing the population for self-protection and mutual assistance are: 


\section{Seccurity}

a) Information and advisory services provided by the education centers, public institutions humanities mission, District Office, autonomous region, municipality, other legal entity or natural person - entrepreneur,

b) Programs broadcast on radio and television and prepared bodies that manage and organize, organize and execute the preparation of civil protection or that their business activities may endanger life, health or property of its employees and the persons taken care of,

c) Publishing activity carried out by issuing professional publications, brochures, puzzles, posters, leaflets, articles in newspapers and magazines on the theme of civil defense and by entities that manage and organize, organize and execute the preparation of civil protection or that their business activities may threaten life, health or property of its employees and the persons taken to care,

d) Preventive educational and promotional activities carried out by the events on the topic of civil protection, in particular, exercises, competitions, exhibitions and excursions, theoretical training and practical training managed and organized by district administrations, regional governments or provided by the municipality in cooperation with public institutions humanities mission,

e) Publication of information in electronic form entities that manage and carry out the preparation of the population for self-protection and mutual assistance, or that their business activities may endanger life, health and property of its employees or other persons.

Based on the above it is clear that currently show a reduced interest of the people to prepare for crisis events. Internal or external motivation is low. This fact is closely related to the informatisation of our society and so. "Congestion" population information to various content and quality. Nevertheless, this fact also contributes to easier access to the necessary information related to the crisis and preparing for them. Decline in motivation to preparedness for the crisis phenomena I see that a large part of the population is quite clearly not feel threatened, which also reflects that we live in a relatively safe society and the prevention and control crisis situations is not neglected, respectively. Has been sidelined in the past, from which we benefit today. The specific sense that the citizens and the population as a whole is important for assessing motivation, because motivation is itself an internal impulse of the individual. If the "mood" of the poor and the population feel they may be at risk to their life, health, property, sufficiently motivated and is preparing to crisis events. At present, 


\section{Security}

they there are not taken all forms of training residents to crisis phenomena in the previous subchapter. These forms of training citizens to ensure that the population is sufficiently informed, preventive prepared and consequently motivated to prepare for the crisis phenomena. It can be stated that the motivation theories currently in the Slovak Republic are hardly applicate in educating and training residents to crisis events. It is the result of relatively complex procedures for the possible application of these phenomena into practice, especially in already cited reasons - lack of interest of the inhabitants of the preparation, respectively, prevention to crisis situations. In Slovakia there is not a comprehensive system of training and motivation of citizens to crisis events. How already mentioned in previous chapters, there are many laws and lowerranking legal rules that government matters. The motivation and training of citizens on a subject is poorly prepared and there are a number of shortcomings. Changes could be realized in the law and in the use of new tools for improved training people. The main forms of training citizens for self-protection and mutual assistance in terms of MV SR Decree. 303/1996 Coll. to ensure the preparation of the CO, as amended, as a very sophisticated and beneficial to society, but after examining the problem it can be stated that these are only "written instructions" to prepare the population to the crisis phenomena. It cannot be said that these forms are used in regular and mandatory recurring intervals. For large positive on the issue of preparedness of the population to incidents in Slovakia and the Czech Republic are public institutions with a humanitarian mission, such as: Slovak Red Cross, Blue Angel, Voluntary fire protection units, ambulances, mountain rescue, and water rescue service. The whole system of education and training of the population to cope with crisis phenomena can be considered as a kind of secondary interest within the public sector. It is necessary to constantly improve the system, to a new and imaginative means of motivation. Within the motivational theories that are mentioned in the previous chapters can be any one of them used to motivate residents. It is up to those in power, they use knowledge disciplines to motivate people. In general terms it can be stated that the problem is the poor state of readiness and training of residents in case of crisis phenomena and their effective motivation. In Slovakia there are many ways to properly prepare residents to cross event. These are not sufficiently utilized, and it is precisely in this area a big problem. In addition to a lack of education and training of citizens on crisis phenomena seen as highly negative the indifference of citizens to prepare to deal with crisis events. If the State took a number of ways and means of motivation population, it would be their 
readiness undoubtedly in better shape than it is at the present time. The problem is that the representatives of the state cannot find a suitable way that the occupant has given a speech on the issue of greater concern. For another problem, ultimately, the lack of interest of the people and this issue. Residents do not appear interested in preparing for crisis phenomena, again related to lack of motivation. They should find appropriate means to motivate residents approached by residents on this matter considerably more active. The problem I see is that it is not enacted a provision that would clearly and precisely determine the procedure for the preparation and motivation of the population to the crisis situation. In general, it can be said that the population has in the Slovak Republic to become well prepared to handle the crisis phenomenon. However, a disadvantage is that it should also show more interest. Do not give him enough attention to the preparation of self-protection and mutual assistance. As a negative can also be considered lack of leaflets, newsletters and sessions with the issue of preparation for crisis events. Another minus is the lack of training and practical exercises on their own people. Regarding the training of children in schools, it is important that this should be better regulated, as it is focused more on theory than on practice in the training of children to civil protection and crisis management. Teachers themselves are sufficiently motivated to be interested in the issue greater. As well as in schools and kindergartens in the system of training young children to crisis phenomena and under-period extra teachers themselves nor do they have a good education about the present subject matter. All courses Civil Protection are actually optional, depending on the population, therefore, how to deal with the preparation for crisis events. Also in kindergartens, teachers do not pay enough attention to preparing children to crisis events. Children are only marginally confronted with this issue. Preparing the population in retirement and sick population has a number of drawbacks, since for these is very difficult to access information. The entire system of training citizens to crisis events operate in the territory of the Slovak Republic as it was only "on paper" and practical use is minimal.

\section{Motivation theories for preparing population to crisis situations}

If we want to examine human behavior in a crisis situation, it is necessary to address the issue of what is causing that one to do so and not otherwise, and forcing a 


\section{Seccurity}

person to act as the right to act. Another important point for the evaluation of the behavior of these phenomena is their subsequent analysis and analyzed on the basis of knowledge is exploring theories that could help to make people behave according to the rules of conduct in crisis situations. Crisis situation, as indeed is clear from the very concept of a "crisis" mostly very unpredictable situation, something unusual, usually hazardous to health, life and property of man. It is important that the company was clearly motivated by the fact that individuals respond properly and deal with the consequences of crisis situations and have them ready in as much as possible. People are aware of the risks to their life, health or property only when participating directly in crisis situations. The consequences of bad theories preparing population for crisis situations shows that ignorance of a suitable response to this situation, or its underestimation with panic multiply the loss of life and show that the given theory motivating the population has not been selected properly or is completely unusable for the situation. Motivation as a psychological and sociological scientific discipline deals with a number of theories to properly motivate residents to be prepared for crisis situations, which does not mean that all the theories are correct. Motivation of population is a very complex process, as they are activated internal assumptions guiding the action of a person to fulfill a certain goal, or of trying to meet certain targets. To the motivation of population and their approach to crisis situations can be used several theories and methods to increase interest population preparedness in case of crisis. (Pommfyová, 2003). The theme is the inner motive that gives and keeps human activities and direct it in a certain direction to a destination, for example. It determines the direction and intensity of behavior and action, as well as the course of the operation. Theme is the core of motivation. Its effect lasts as long as the goal is achieved and until the target satisfy us. Subjective motivation is self-motivation a person to certain proceedings both at work and outside the working environment, while objective motivation is the ability to motivate people to perform certain one-time or recurring activities. Motivation can also be divided into positive motivation and negative motivation. The term is understood to motivate positive motivation through positive incentives such as self-realization, moral valuation, and tangible benefit. It follows that negative motivation is based on a form of punishment or fear, for example, fear of losing work. There are several theories seeking principles, patterns, methods and tools on how to effectively motivate people how to direct their efforts and effectively lead to the achievement of the goals. Motivation theories on the basis are divided into content 
theory and process theory. Content theories address the question of what really motivates people, explaining their motivation in terms of needs, specifying the various needs and clarify some dynamic changes in needs. Process theory explains how arise motivation at work, explaining their motivation in terms of perceptions, expectations prerequisite for achieving the satisfaction of needs.

The first of the most important motivational theories is Adams' theory of justice. Adams's theory of justice is among the theories dealing with motivated people. It was published by John Stacey Adams in 1965. It is based on two levels. Remuneration in respect of some great performance is right according to comparable data and reward is right and example to other colleagues at work, that is fair. When people feel a sense of justice that motivates them to higher performance and sense of injustice performs the opposite effect, that their performance will be weak, which means mainly to prepare population for crisis situation disinterest in the subject.

John Stacey Adams theory refers to as material and non-material needs, rewards. Another theory dealt with the American psychologist Abraham H. Maslow. He came to the view that every human behavior is driven effort to meet their basic needs. These needs, according to him can be arranged in a pyramid with the base physiological needs, the needs of safety and security, needs and requirements of love, and the need to recognize the most important motivation for the theory of self-actualization needs. Explanation of the pyramid is as follows. A person first needs to satisfy their basic physiological needs such as breathing, drinking, eating. When a person feels the need of safety and security as well as requirements and love shifts to the need for recognition and self-realization, which is in connection with motivation population to crisis preparedness that should be given space residents to be realized also for this preparation.

As a further theory in turn it is Alderfer motivational needs theory by Paul Clayton Alderfer. This theory is based on three motivational factors:

- The existence of job security,

- Relations, e.g. friendship, recognition of the social network,

- Self-realization, for example, possibility of professional growth.

The use of this theory in practice is the satisfaction of subsistence needs, and then satisfy relational needs, which will ultimately lead to meet the needs of selfrealization. 


\section{Security}

The following theory is Herzberg's theory of two factors. Two-factor motivational theory was formulated by Frederick Herzberg in 1959 and named in this theory are two basic factors that are the source of population satisfaction and motivation. The first factor is non-satisfiers, including those which cause the working dissatisfaction. The second factor is satisfiers (motivators), including those that help energize motivation and satisfaction. In practice, this means that the non-fulfillment of hygiene factors cause dissatisfaction, while working, but their fulfillment does not because a feeling of satisfaction, it takes them for granted and their effect wears off quickly filling. In contrast, the fulfillment of motivational factors is a prerequisite to motivation to higher job performance and their effects on motivation was long and their non-fulfillment does not necessarily mean dissatisfaction.

A fifth theory is Taylor's theory of motivation formed by F. W. Taylor as the father of scientific management, which took the view that with the scientific approach it is possible to improve the performance of workers. He focused on the examination of a person, especially as building management. Its aim was to maximize the outcome of their work while minimizing its consumption. Important nature of the material motivation of workers and of man understood as an economic entity, which means in practice in order to encourage citizen preparedness for crisis situations, that if he was financially motivated to undertake training and exercises in an emergency situation would be less loss of life, health and property.

The next is May's motivation theory, founded by E. Mayo. He examined the impact of psychological factors on the results of human labor. The need to respect the staff to the social conditions of their activities opposed the concept of scientific management. The basis of his work is that they all work, process conditions, and physical needs of people tend to have less impact on the work, but social and psychological factors. He stresses the importance of social relationships for work motivation. To use this theory to motivate citizen to crisis preparedness can be said that the people should participate in exercises and training in crisis situations if their completed with residents with whom they share common interests and direct social relations.

Another theory is McGregor's Theory $X$ and Theory $Y$. Under certain circumstances, leading people through the right incentives are most effective form of this process. Theory $X$ is the implementation of the central leadership principles set of guidelines, the command and control of personnel management, which is the realization 


\section{Seccurity}

of authoritarian forms of governance. Theory $Y$ management represents the style which is based on the integration of the interests of members of the organization by working towards their own initiative and choice of funds under specified conditions, in order to achieve the objectives. Theory $X$ is authoritative, pessimistic, static and rigid. Theory $Y$, by contrast, dynamic, optimistic, resilient. It is recommended not to use only the style of $X$. The possibility of using this theory to motivate citizen to crisis preparedness is that residents should be encouraged to be interested in preparing for emergencies, so as to meet their psychological needs of the interests of the very motivation. The last two theories are equity theory and the theory of expectations. Theory equity (fairness) deals with human perception as it is with individuals treated. This theory assumes that people will be more motivated if they would be treated fairly and demotivated when they will be treated unfairly. In this theory they are embedded two forms of justice and it is distributive and procedural. Distributive justice is concerned with how people feel that they are remunerated according to their value compared with others. Procedural justice has to do with how employees perceive fairness of the procedures used in the organization in areas such as staff evaluation, promotion and disciplinary matters.

The last theory is the theory of expectations. It's best known, most successful theory and complex models of motivation theory as equity. It has multiple versions and different name. It is a model based on the conscious thinking about the situation. According to this theory, motivation depends on two factors ranging from how many in that we want to achieve something and the probability with which we expect to do this. Model theory of expectations was developed by Victor Vroom. He defined motivation as the process of guiding the choice of alternative forms of volunteering. The motivation to act depends on their expectations of what the results will be for activities to follow. The basic model of motivational theory expectations include the following procedures:

- motivation leads to efforts,

- effort, combined with the ability and the environmental factors results in performance,

- Power leads to different results when each of them is associated with values.

Utilization of theory of expectation into practice is based on the recognition that each person adapts its work effort according to their subjective beliefs about the reachability and the attractiveness of the target, so that as you answer the following questions: 


\section{Securiatity}

- Is the aim for me attractive?

- Is it likely that I fulfill a task?

- Is it likely that the role to be fulfilled obtain a remuneration corresponding to my expectations?

The use of this theory to motivate citizen preparedness for crisis situations is that the citizen is indirectly motivated.

All the theories mentioned in this article are applicable, to a certain extent to motivate citizen to participate in training, exercises and general preparation and how to manage a crisis with as little loss.

The greatest rates of utilization of motivational methods have equity theory because this theory is to motivate residents can contribute just as much to the people will be more motivated if they would be treated fairly and demotivated when they will be treated unfairly. It should be treated with residents really fair, accessed by the crisis preparedness responsibly. But the biggest motivation for residents at this time is likely to be material needs, which means that if the people receive such financial reward for their participation in training, exercises and training residents to crisis situations. Also, it can be said that the residents will feel preparedness for crisis situations, they will feel safer and more confident, which is very interested in self-motivation to prepare for emergencies.

\section{Conclusion}

Each of the above motivational theories could be used in relation to motivating residents to prepare for crisis situations. However, if residents do not engender confidence among the heads of state, it is difficult to motivate them to approached the issue responsibly and prepare for the crisis phenomena. Except from equity theory there is a scope for application of the theory of expectations and not least in the classical theories of Taylor, who claimed that people can be motivated mainly by financial rewards. It can be said that in general readiness of the population to crisis situation is not sufficient and the internal and external motivation for crisis preparedness is not given almost no attention. This primarily relates to the responsibility of the competent government authorities, municipalities and other 
interested organizations and schools for the population's state of preparedness for crisis situations.

For example, in the system of legislative adjustments SR essentially no comprehensive legislation that would comprehensively determine all the necessary documents for cross training of citizens and not the actual theory. Based on the theoretical background of the preparation of the population for crisis situations are clearly the issues that bind to motivate population to emergency preparedness.

\section{References}

1. Antušák, E. (2009) Krízový manažment - úvod do teórie. Praha: VŠ ekonomická.

2. Míka, V. (2009) Manažment a krízový manažment. Žilina: FŠı ȚU.

3. Pomffiová, M. (2003) Spôsoby motivácie a tvorba vztahov v nových podmienkach globálnej ekonomiky. Banská Bystrica: Univerzita Mateja Bela, Ekonomická fakulta.

4. Klučka, J. (2013) Ekonomika krízového manažmentu. Žilina: Žilinská univerzita: Edis 